\title{
Application of Green Collaboration Operation on Network Industry
}

\author{
Yeh-Cheng Chen', Chi Nung Chu'², Hung-Min Sun', Ruey-Shun Chen²,", Ling-Chi Chen ${ }^{3}$, and Chia-Chen Chen ${ }^{4}$ \\ 1 Institute of Information Systems and Applications, National Tsing Hua University, Taiwan \\ 2 Department of Information Management, China University of Technology, Taiwan \\ 3 Institute of Information Management, National Chiao Tung University, Taiwan \\ 4 Department of Information Management, National Chung Hsing University, Taiwan \\ \# Corresponding Author / E-mail: chen1868@gmail.com, TEL: +886-35610199, FAX: +886-35610616
}

KEYWORDS: Green collaboration operation, Management system, Green supply chain, Green products, Product recycling management

Traditional information system and managerial mechanism cannot meet the new environment protection regulations; therefore, a new solution must be set up, else it may run the risk of losing the market and the value of product brand.This research focuses on the solutions provided by the network and communication industry, manufacture of the green products, and the establishment of a Webbased green collaboration management system, which incorporates the environment protection requests into the product development and green supply chain activities. There are three goals: (1) For the design of green products, green components and product management are set up for the purpose of de-toxin and ease of disassemble; (2) For the green supply chain, the management of hazardous substances, product recycle and disassemble are set up; (3) For the product recycling management, the recycling information is feedback for the product update and collaboration operation. The result of research can provide information for the integration of workflow and information system currently in use, provide RoHS and WEEE management solutions, and set up green collaboration information system, so that green products, brand leadership, and environment protection endeavor can be assured.

\section{Introduction}

With the earth warming getting worse and new electric and electronic products always coming out, environment pollution becomes more serious. Therefore, nations in the world are actively enacting environment protection regulations, and EC-published RoHS (Restriction of the Use of Certain Hazardous Substances in Electrical and Electronic Equipment), ${ }^{2,3} \mathrm{EuP}$ (Eco design Requirement for Energy Using Product) and WWW (Waste Electrical and Electronic Equipment) are three most important codes, which cast tremendous impact on the electrical and electronic products. If not properly meeting the requests and regulations of the EC codes, it may run the risk of losing the market and the value of product brand. ${ }^{18}$

In the past, the functionality and quality of the products are more emphasized, and the environment protection is beyond consideration, which leads to the failure to meet the requests and regulations of the EC. To confront with more issues of environment protection, a new managerial mechanism and information system is expected. Much emphasis on past industry functional stability and quality of products, pollution prevention and control of environmental issues, mostly in post-production process reprocessing generated pollution and waste problems. With increasingly stringent environmental requirements, such as the cost of treatment is not only gradually improved, even secondary pollution problems, so developed one of the sources of environmental norms into product design will be developed and parts recognize priorities projects; for $\mathrm{RD}$ selection to ensure compliance with standards of environmental protection, the need to build the customer's specifications and green environmental protection product part database to assist.

Traditional supply chain management and more focused on MRP, inventory management and improve customer satisfaction and other issues, can not address new environmental requirements; core products in order to check compliance with the customer's specification, first of all to determine the next step for all products are in compliance with the material specification, so you must go step by step through the upstream vendors require third-party verification of environmental test data, and then through the Part table, these harmful substances and materials stacked recyclable survey information to the product order 
volumes, analysis and management; majority Netcom products will use the material to more than a hundred, and the company's products to several hundred, to collect information on such a large, must build a web platform for the exchange of information management and information system suppliers to meet RoHS, WEEE and EuP requirements. ${ }^{5-8}$

The traditional product design and supply chain activities are not mentioned in the final waste recycling issues, has been unable to reach the WEEE requirements, the need to establish a management mechanism and information systems; produce dismantling exploded diagram, and the integration of IT market recovery side, the results back to R \& D units, as the basis for product design improvement. ${ }^{10-13}$

Traditional information systems listed above can not solve the problem, evaluate and introduce appropriate environmental design and supply chain management tools to help turn is one of the important work of them. Build a green collaborative applications, coordination and management of internal. ${ }^{14-17}$

This research is expected to provide solutions to the issues mentioned above, and attain the following objectives:

(1) Establishing the management mechanism of green products:

- Collecting the environmental criteria of clients and incorporating them into the product design

- Shortening the design schedule of green products and becoming the leader in the green product market

- Establishing the management and review mechanism of the green product vendors

- Recycling info feedback to the R\&D units for the everlasting endeavor of the product design improvement

(2) Establishing the information application system of green products:

- Establishing the design platform of green products

- Establishing the management platform of green vendors

- Establishing the recycling platform of wastes

(3) Integrating the operation workflow and information system for the maximized efficiency

\section{Literature Review}

\subsection{Green Collaboration Operation: Definition}

In order to manufacture the environment protection-compliant green products, the integration of clients $\rightarrow \mathrm{R} \& \mathrm{D} \rightarrow$ vendors $\rightarrow$ Manufacture $\rightarrow$ Recycling must be implemented.

\subsection{Codes and Regulations of Green Environment Protection}

Nations in the world and NGOs(Non-Government Organizations) are actively enacting localized environment protection codes and regulations, and EC-published EuP, RoHS and WEEE are three most important among them.

\section{RoHS}

RoHS stands for Restriction of the Use of Certain Hazardous Substances in Electrical and Electronic Equipment. RoHS, 2,3 enforced on July, 2006, rule out the use of six restricted substances: lead( $\mathrm{Pb}$ ), cadmium(Cd), hexavalent chromium $\left(\mathrm{Cr}^{+}+\right)$, mercury $(\mathrm{Hg})$, polybrominated
biphenyl(PBB) and polybrominated diphenyl ether(PBDE). These restricted substances are gathered into the product with the supply chain system during the production process. Therefore, the control operation of the restricted substances must pace with the management of the supply chain so that the restricted substances can be ruled out., ${ }^{4,9}$

\section{WEEE}

WEEE stands for Waste Electrical and Electronic Equipment.

EC-activated environment protection has been through the legislative process, and the handling of electrical and electronic wastes is the primary concern. These regulations have been enforced on August, 2005. They covers the collection, recycling, handing of electrical and electronic equipments, they also cover the regulation of user-supplied information. There are 10 major categories, and more than 100 products are covered. The main objective of $\mathrm{WEEE}^{1}$ is: 1 . cutting down on the quantity of EEE wastes; 2 . less EEE wastes left in the waste yard; 3 . increase of the percentage of resources reuse.

\section{EuP}

EuP stands for Eco design Requirement for Energy Using Product. It was enforced in 2007. Environment Protection Design Parameters of EuP

(1) Major environment consideration in each phase during the product life cycle $^{19}$

(2) Factors evaluated in each phase: expected consumption of energy and resources; expected emission of air/water/soil pollutant; expected contamination of noise/vibration/radiation; expected output of wastes; feasibility of recycling and reuse of resources/energy.

Impact of Environment Protection Regulations on the Network and Communication Industry:

(1) Of the ten major EC-regulated electrical and electronic products exported to Europe from Taiwan, nearly $60 \%$ of them are from network/communication industry.

(2) The primary sale areas for the third quarter in 2005 are North America, Europe and mainland China, which count $31.1 \%$, $32.0 \%$ and $13.3 \%$ respectively, and Europe is the topmost export area (32\%).

\subsection{The Integrated Application of Green Life Cycle Design}

The central idea of green design of Green Life Cycle Design (GLCD), the design features not only how to recycle both the waste, more important is to make the designer in concept formation. Before we consider the future of the development of products, each stage in the life cycle of all the green may have the resources input and output, so product designers should design, it is necessary to consider the environmental effects of the various stages, while the life cycle and the beginning of the end to be linked, as far as possible through the reuse or recycling of the way, the waste material can be completely recycled and reused as a new product, and reduce the use of toxic substances and scarce resources to increase energy efficiency. Product designers in the design of any of the products, the product should be from the entire life cycle considerations, to develop environmentally friendly products, green design integration system programs or services, which is effective from the product materials, design, manufacturing, packaging, transportation, use the end of the waste, are to take into account the use 
of resources, prevent pollution and ecological balance problems and try to improve the environmental quality continued to deteriorate, the product impact on the ecological environment to a minimum. ${ }^{19-23}$

Life cycle assessment and considerations, but also for later meet EuP, while production and provide eco-profile common practices. For WEEE regulations, the brand manufacturers need to implement in accordance with EU rules, the product belongs to WEEE categories, as well as reuse, recycle, recovery and other $3 \mathrm{R}$ product evaluation, providing information including product easy to disassemble instructions to complete the registration before the prescribed time limit EU countries obtain registration code; must also sign a contract with the government or local recycling systems industry, build complete recycling system.

Supply was also confirmed that the upstream supply chain can provide timely and reasonable prices, while meeting the delivery requirements of green components, and to collect and compile the components are RoHS compliant concentration of six ingredients of controlled substances information related to not using cut knot that is. This wave of green supply chain management counseling, you need to clearly inform suppliers of green specification requirements related to content, dismantling methods, content and format of information to fill in the declaration described, with the flow and delivery schedule, simultaneous testing and certification, auditing, etc. and other relevant measures to ensure that incoming conform itself with the customer's green specifications, but also in order to enhance physical fitness and preparedness of the supplier of green product management; also need to be switched with lead free solder process equipment and management processes, implementation staff education and training, in order to confirm the incoming and process which will not produce pollution, to ensure that products meet green specifications $\mathrm{s}^{24-27}$ as Fig. 1.

\section{Current Status of Collaboration Operation in the Network and Communication Industry}

\subsection{Case Study}

The case study company is a network and communication manufacture located in the Taiwan Science Industrial Park as Fig. 2. Founded in 1989, the major customers are telecommunication service provider / enterprise / family / end user. This company has strong brand advantage in Europe, has honor of the biggest DSL router manufacturer worldwide and especially in Europe for consecutive four years, and has brand leadership advantage. In addition, it is honored one of ten Taiwan-made brands, having the most valuable brand in the network and communication field. Its primary products include: DSL broadband client-end and office-end communication equipments, broadband network security equipments, routers, ISDN terminal adapters, and modems.

The products of the company under study belong to Category 3 among ten major EC-regulated electrical and electronic products, i.e., information and communication equipment. Sales amount in Europe counts $53 \%$ or more, and that of brand products in Europe counts nearly $90 \%$. Therefore if not properly meeting the requests and regulations of the EC codes, it may run the risk of losing the market and the value of product brand.

With the environment protection getting more concern, the enterprise must bear the citizen obligation in mind. In addition to the pursuit of the enterprise profit and perpetual survival, the protection of environment and ecosystem is also a major object.

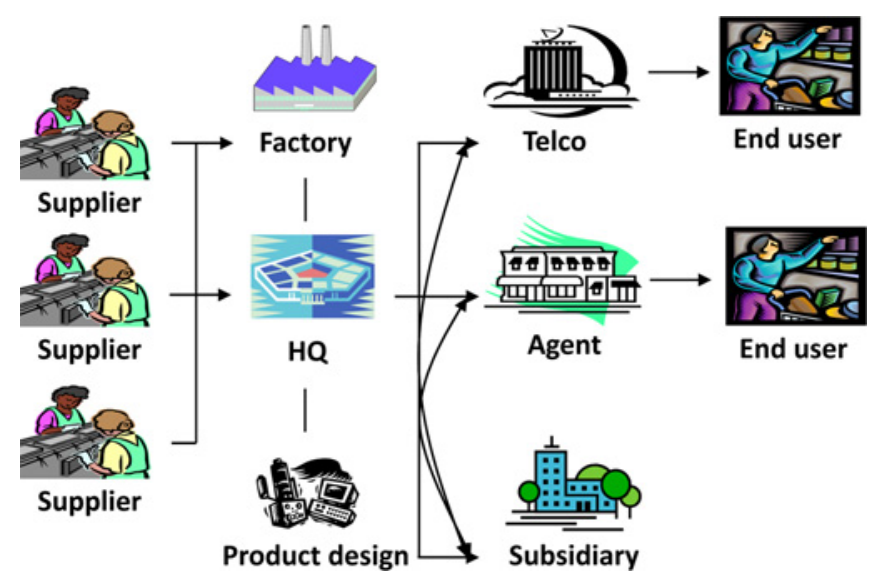

Fig. 2 Business Operation Flow

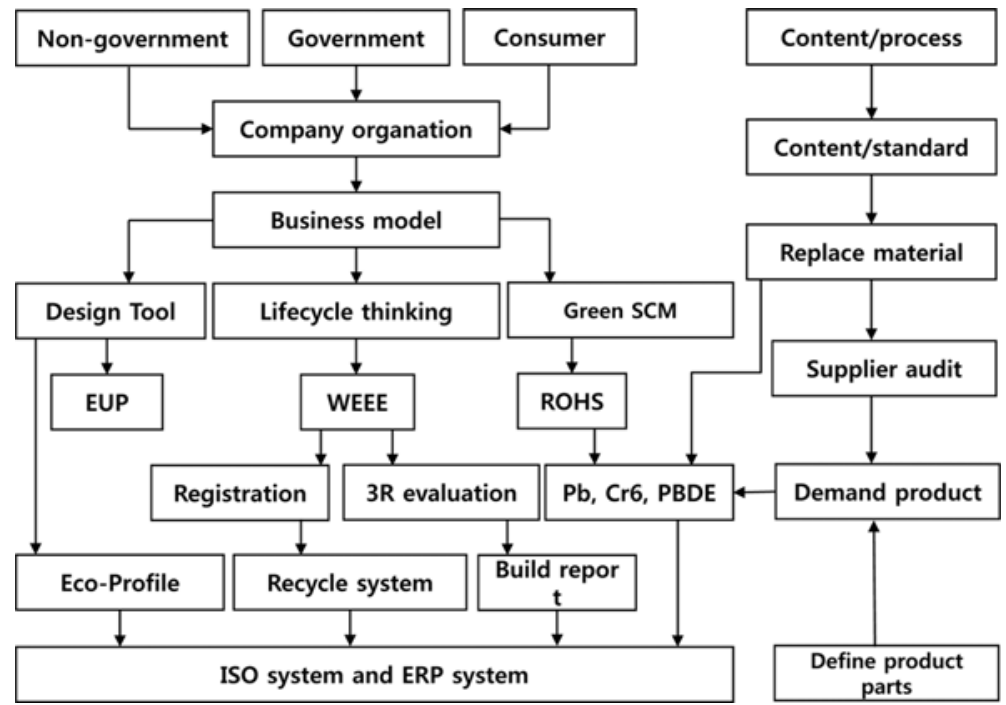

Fig. 1 Integrated application architecture of green life cycle design 


\subsection{Analysis of the Business Operation Mode}

Business headquarters in Taiwan and the mainland all are equipped with the research and development center and the factory; First can obtain from the client side produces the moral character demand, and carries on the product design, the production and the sale; In sells goods the circuit aspect, direct or the indirect penetration subsidiary company sells the product with the business agent and the telecommunication bureau, finally resells again to the terminal user on

\subsection{Analysis of the Product Development}

After receives the customer demand specification, enters to the Proposal Phase C0 stage, carries on appraisals and so on Proposal and feasibility, if OK, then enters to the Design Phase C1 stage, launches composition work and so on special case team, product development. Afterwards, enters work and so on function and reliability testing which to $\mathrm{C} 2$, the $\mathrm{C} 3$ examination delivers, must strengthen the tube especially in the $\mathrm{C} 3$ stage to control the product the function and the quality. If OK than pass to first Customer Shipment (FCS) stage, and generate FCS testing report, QE reliability testing report. Afterwards, the product enters to the quantity produces (Mass Production) the stage. Afterwards, the C5 stage then examines the service policy. Finally enters to End of Life the (EOL) stage. Show in Fig. 3.

\subsection{Problem Define and Analysis}

Shows production plan flow in the front section introduction, in the past all flows all were unable not to consider the sales green product grew the design and the coordination question, have been unable to satisfy present the service demand, the following list it to face the question and the analysis.

(1) The traditional information system has the following question: Unable to manage the customer the environmental protection standard

- Unable to collect the components material examination table the material.

- Unable to provide sufficient information to $\mathrm{RD}$ when the product design chooses the material.

Unable the control product whether conforms to the environmental protection standard.
(2) The past product development and the supply chain flow, did not have any environmental protection demand management mechanism.

(3) In the past enterprise many emphatically in product function and quality is unable to provide the environmental protection laws and regulations request the correlation report.

\section{System Design and Analysis of Green Collaboration Operation}

\subsection{The Strategy of Green Collaboration Operation in Network Industry}

Facing the European Union two big environmental protection instructions, formulates RoHS and WEEE in accordance to the strategy. The leading market promotes the green product, guarantees the brand market leading positions and the strengthened environmental protection image, and causes the threat to transform as the opportunity. Therefore subscribes carries out the strategy surely, following shown in Fig. 4. It was divided into three construction surface also to carry on: First for green product development: Collects the customer environmental protection standard first, then carries on the product design, and makes the environmental protection compliance control movement; Second manages for the green supplier: Penetrates supplier's management and counselling collects the material environmental protection information and in the components acknowledged in the flow inspects the material the environmental protection compliance; Moreover the hope the components which establishes with the aid of the trade union uses in common the platform to enhance the news collection the efficiency; Third for recycling management mechanism: To RD makes the product design improvement again the market end actual recycling information back coupling; And penetrates the information system conformity and passes through three between the information's, forms close loop the management.

Strategy of RoHS:

- To enhance customer relations, obtains the green standard.

- Integrates the research and development design key the RoHS

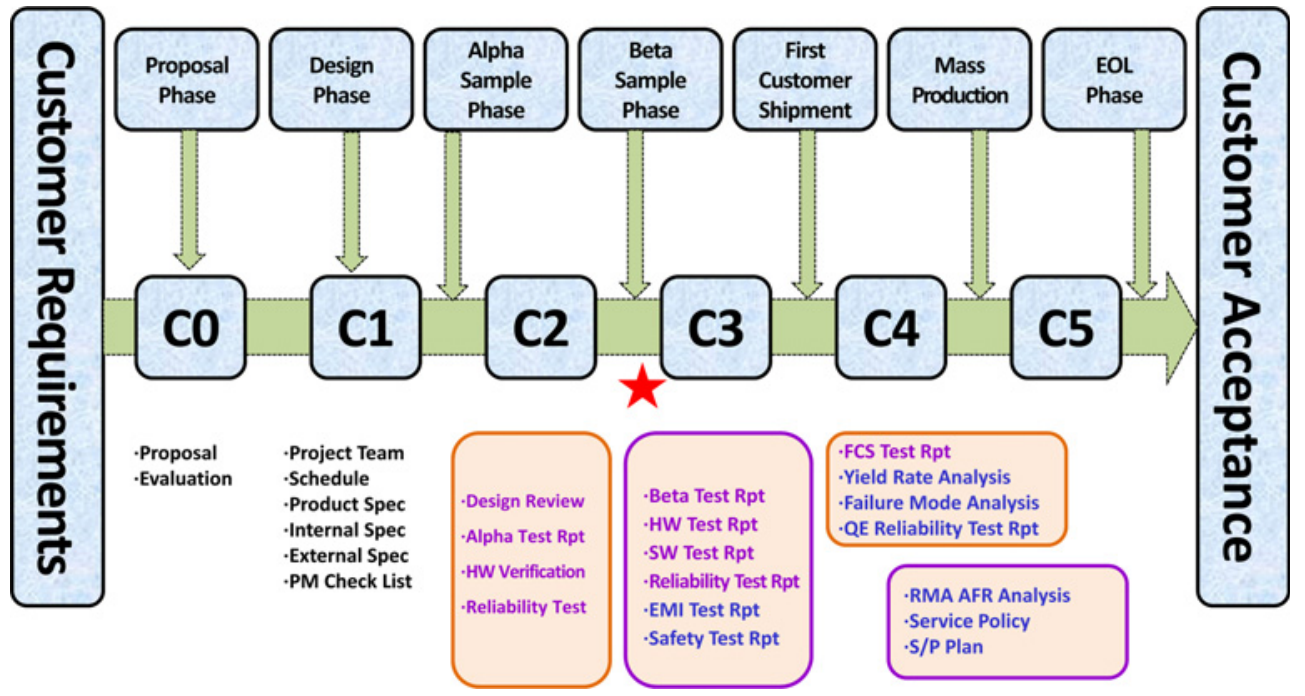

Fig. 3 Product development flow 
standard.

- Reduces the management cost, all products cut the green product.

- To reduces the delay material stock in transformation period.

- To enhance the supplier management, make sure the source is green material, reduces each other the management cost.

- To integrate existing operation flow and exterior green components information platform.

- To implement a green coordination information system, enhances the efficiency, reduces the management cost

\section{Strategy of WEEE:}

- To enhance customer relations, obtains the green standard.

- Designated the quantity sells Europe's product greatly, establishes the forerunner pattern (easy to explode /easily to recycle design).

- The forerunner pattern must easy duplicate the use, easy to copy to another country.

- The WEEE standard is a key point of research and development design

- To implement a green coordination information system, enhances the efficiency, reduces the management cost.

\subsection{The Business Model of Green Collaboration}

The establishment company in the new environmental protection time prospect is, according to European Union laws and regulations, customer green standard request, formulation company itself green product environmental protection policy, for example: ISO-9000 and ISO-14000, conform to the green environmental protection correlation requirement.

Starts from the customer relations management important source, to establish the market and the customer green standard, penetrates the middle supplier to manage the counselling standard, launches the supplier to screen, the supplier investigation, supplier counselling and so on took, promotes the supply chain partner green management physique with fitting out. When product FCS and shipping to customer, to collect customer and the 3 party feedback the recycling processing information automatic by system to provides for units and so on research and development improves the product design.

In the product design aspect, establishes the green standard, with the actuation green design tool, if the establishment green part information bank with checks the table, facilitates RD to choose the material and the design, and connects exterior part information bank, the acceleration substitution source of raw materials inquires the type; And remodels the material number and the components acknowledgment flow, connects exterior confirmation information platform, the acceleration components confirmation information confirmation.

Take transport business headquarters as the core, manages the platform from internal establishment green standard and the information, counsels the supplier to complete the green supply chain management, requests the supplier to provide the components RoHS control material the ingredient information, future and will counsel the supplier to have gradually replies the EuP information ability. The penetration collect green part information and the information bank, the green product design flow servo system, develops positively conforms to the market and the customer request green product.
In the product design aspect, establishes the green standard, with the actuation green design tool, if the establishment green part information bank with checks the table, facilitates RD to choose the material and the design, and connects exterior part information bank, the acceleration substitution source of raw materials inquires the type; And remodels the material number and the components acknowledgment flow, connects exterior confirmation information platform, the acceleration components confirmation information confirmation In the product design aspect, establishes the green standard, with the actuation green design tool, if the establishment green part information bank with checks the table, facilitates RD to choose the material and the design, and connects exterior part information bank, the acceleration substitution source of raw materials inquires the type; And remodels the material number and the components acknowledgment flow, connects exterior confirmation information platform, the acceleration components confirmation information confirmation

The penetration sells Guang Xuan to move, reveals suddenly with the promotion company and the product environmental protection image. The penetration subsidiary company relies on the various countries' standard with each place business agent, collects the European Union various countries recycling laws and regulations information, implements the regulation and the time interval according to various countries' WEEE, completes the registration, reminds the recycling finance to guarantee, with using local recycling system signing, establishes the recycling processing monitoring mechanism. The establishment (including recycles foothold, recycling business signing) take Germany and Holland as the basic management pattern colored woodblocks European Union various countries recycling system mechanism, collects puts in order with the monitoring various countries abandons the product recycling processing condition, the penetration recycling information back coupling and the analysis adds the value activity, reduces the product whole recycling cost, and promotes the product the design benefit; Simultaneously may duplicate the transplant to abandon the product recycling management mechanism fast to other countries, utilizes the product recycling effectively the best management work, reduces the management to abandon the product the recycling cost.

Future the application scope simultaneously will integrate the Taiwan transport business headquarters and the mainland factory, will promote Taiwan and the mainland supplier management gradually, and will carry on works and so on factory system regulation transformation, transport business foothold first integrates 16 subsidiary company/ subsidiary companies and all 3 research and development design center, and will facilitate in 70 country's all business agents (sells foothold including the European Union market as well as whole world) all to be able to penetrate the network to obtain with the back coupling product correlation information, this plan green product, the supplier and the recycling management achievement will publicize for the global 150 country's consumers (including telecommunication selfmanagement business, enterprise user and family and individual user).

The comparison at present transport business pattern, the future transport business pattern, following shown in Fig. 4.

\section{Green product design}

(1) To establishment green standard and the components database for research and development to choose the material and the design. 
(2) Connects exterior common components infrastructure, to enhance the efficiency in second source of raw materials inquires and the components acknowledgment effectiveness.

(3) To improve the part and acknowledgment flow.

Green supplier management

(1) To establishment green supplier manages, counselling, the investigation to make sure the source is green component.

Product recycle management

(1) Collects the European Union various countries recycling laws and regulations information.

(2) Establishment recycling monitoring mechanism.

(3) Product recycling indication.

\subsection{Operation Flow of Green Collaboration}

In accordance to the green environmental protection request, the union existing transport business flow and the information system improve, guarantees the product to conform to the standard, therefore in the product research and development flow, the supply chain management and the components acknowledged the flow, in the green product manufacture flow joins the check point; And the new addition with abandons the product recycling with the exterior common components information platform conformity. This research classifies the work pattern three mold trains, the green product design, the green supplier and the components acknowledgment management and the green product recycling management, the distinction states as follows:

\subsubsection{Green Product Development Flow}

Front end penetrates the environmental protection specification material management mold train, the collection collects the entire customer and the laws and regulations green standard, and according to decides on the green standard, holds the conference examination and the confirmation final green product detail specification by PM.

Next, inducts the green part information bank establishing with the connection, the rich green product design knowledge library, the accumulation experience, the reduced redundant design mistake, becomes the green design the expert servosystem, the acceleration product development speed. In the product development flow $\mathrm{C} 0-\mathrm{C} 1$

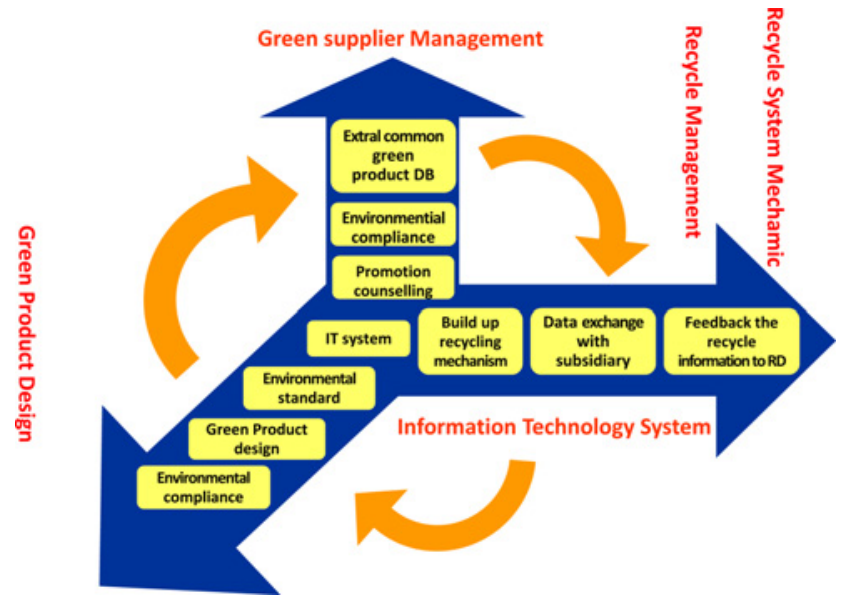

Fig. 4 Strategy of green collaboration examination stage, will then collect the product recycling information and the experience green design instruction knowledge library (RD design guildline DB) integrates the product design inspection checking, in the product development flow $\mathrm{C} 2$ examination stage, the material which the tracing product not yet acknowledged, will urge the product all to conform to the environmental protection requirement in the quantity pre-natal all material qualities; Accumulates the product design practice experience and the rich knowledge library judgment criterion continually.

Part material provides which according to the supplier, establishes the part information bank, facilitates the research and development to choose material as well as product shifting work checking, satisfies the province to be able, to reduce, the reduction waste/reduces the product, Yi Chaijie, with the design request which easy to recycle; And in enters in front of $\mathrm{C} 3$ to check the BOM compliance; In order to guarantee conforms to the RoHS standard, RD/PM components acknowledgment when collects the material deleterious substance ingredient value, penetrates the BOM table the step all material deleterious substance to add the product under always, rates this product whether conforms to the environmental protection standard RoHS requirement. Part material provides which according to the supplier, establishes the part information bank, facilitates the research and development to choose material as well as product shifting work checking, satisfies the province to be able, to reduce, the reduction waste/reduces the product, Yi Chaijie, with the design request which easy to recycle; And in enters in front of $\mathrm{C} 3$ to check the BOM compliance; In order to guarantee conforms to the RoHS standard, RD/PM components acknowledgment when collects the material deleterious substance ingredient value, penetrates the BOM table the step all material deleterious substance to add the product under always, rates this product whether conforms to the environmental protection standard RoHS requirement.

And continues thoroughly the traveler to take the recycling management, according to Dutch and the German different recycling system, and confirms the adjustment gradually with the establishment recycling information management system management system embryonic form, the accumulation managerial experience, and may duplicate fast and shift to the different country, reduces different national the management to induct the time and the reduction manages and recycles the cost of operation. Launches the correlation from $\mathrm{C} 0$ to the $\mathrm{C} 5$ various stages product development flow the coordination work. Following Green product development flow are shown in Fig. 6.

The next presentation of hazardous substances and products in line

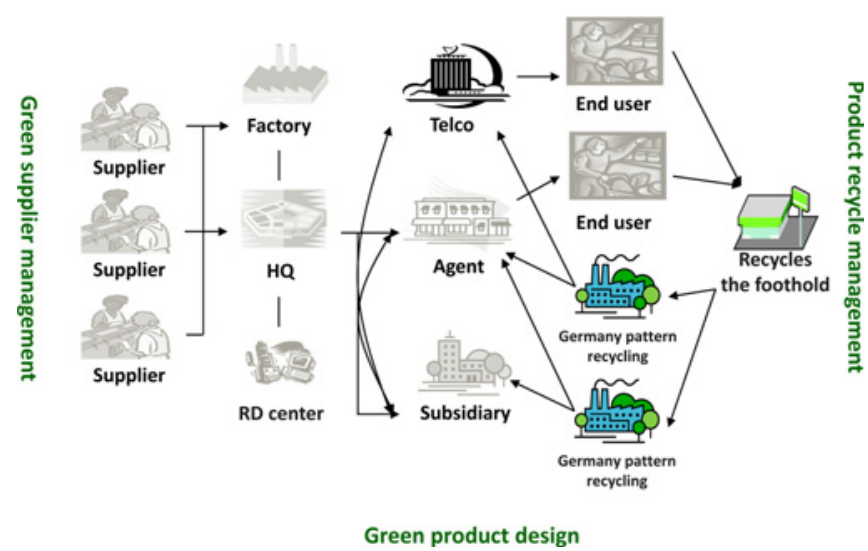

Fig. 5 The business model of green collaboration 
with the rate of recovery to reach compliance checklist of process specifications. The following section describes the parts combine to recognize processes, $\mathrm{RD} / \mathrm{PM}$ will usually $\mathrm{C} 2$ to $\mathrm{C} 3$ stage, the weight of collected recyclable parts recognize the value of the material composition of hazardous substances and materials, warning signals that the product meets the specifications through the system, If the next stage by feeding table can be expanded through the system to the list of materials that unusual, and then back to the supplier requires feedback to improve; if they meet the specifications of the product will allow to take effect, enter $\mathrm{C} 3$ stage. As shown in Fig. 7.

\subsubsection{Green Supplier Collaboration and Components Acknowledgment Flow}

The enterprise supplies the related work flow in accordance to the green which the chain the transformation extends, including components selection with acknowledgment and. The purchase feeding examination question, the enterprise the work like belongs to many suppliers to a system manufacturer construction, then belongs to green of supply chain information management demand the individual central factory, still was purely; If the condition is many suppliers can become complex to many system manufacturer construction condition many, therefore the TEMMA establishment is a feasible way, and may avoid examination document exchange and the artificial material the inefficiency constructs the files, guarantees the electronic components specification/examination material the accuracy.

\subsubsection{Product Recycles Process}

The brand company confirmed first must tally the standard, provides the statistics to sell to the European Union various countries the year sale quantity and the weight, the accumulation abandons the product year to recycle quantity and the weight, as well as year goal information's and so on recycling quantity and weight provides to the various countries' environmental protection regulatory body registration, guarantees achieved even surpasses the laws and

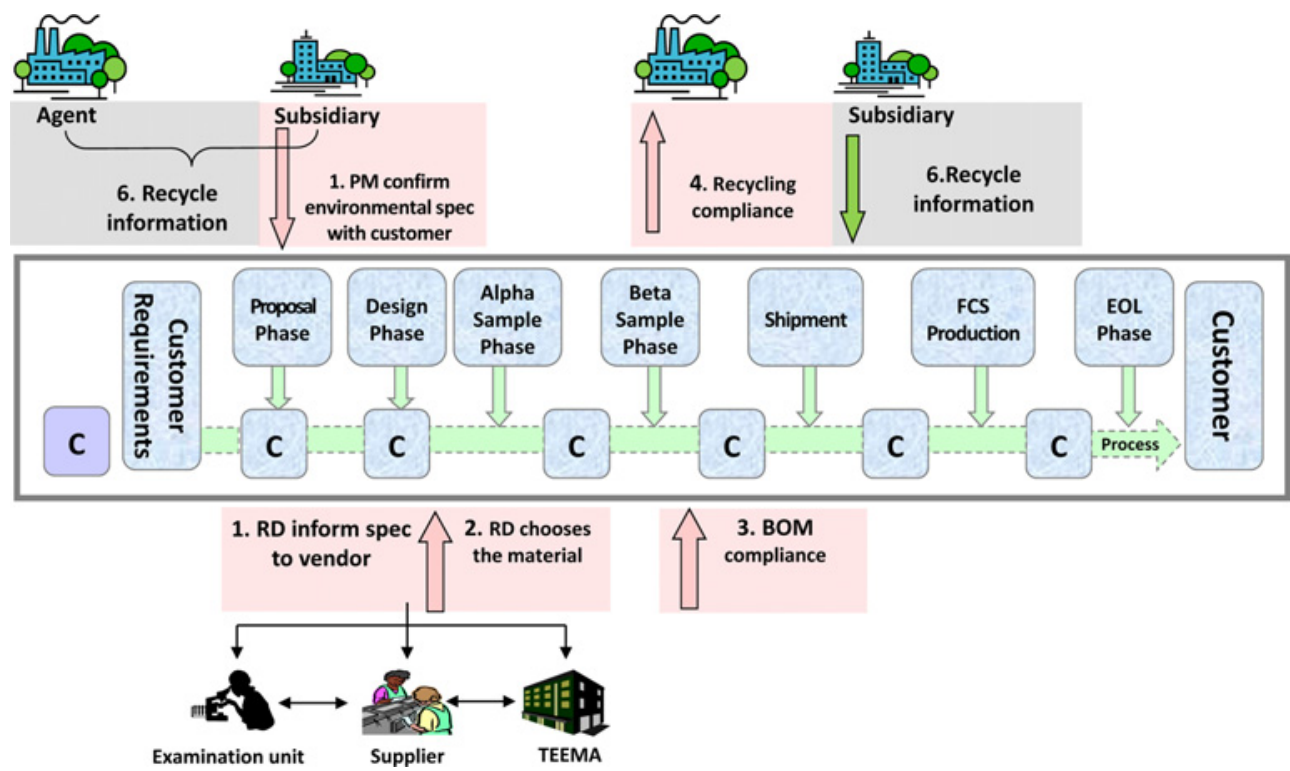

Fig. 6 Green product development flow

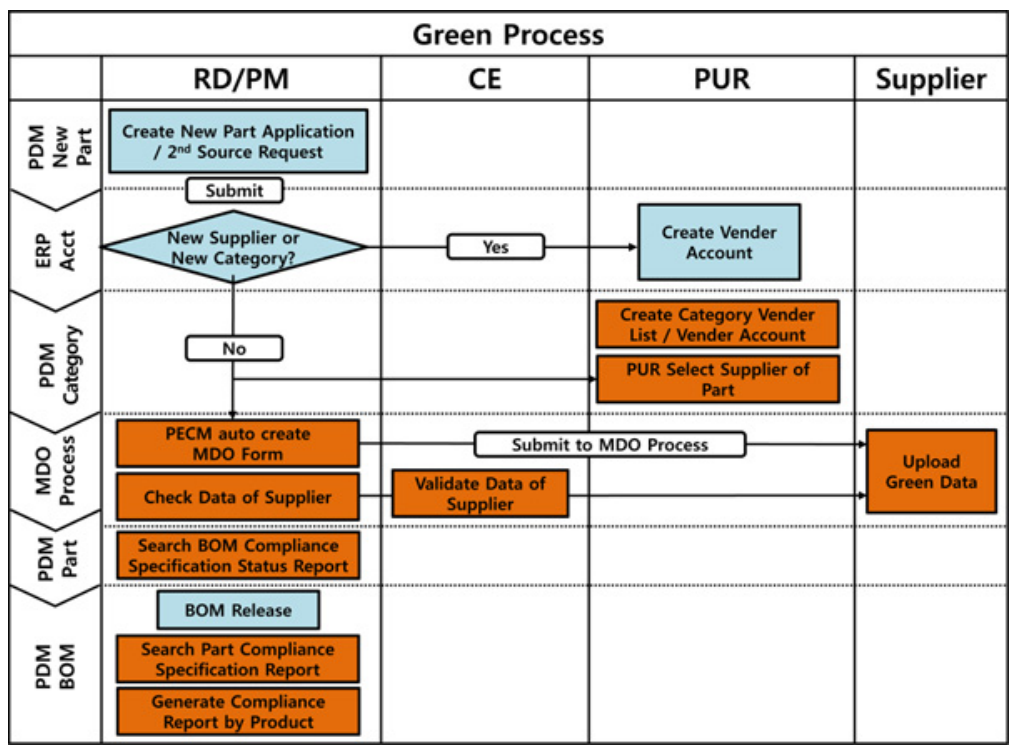

Fig. 7 RoHS hazardous substances checklist of process checklist of process flowchart 
regulations regarding to abandon request the product recycling weight ratio; And will research and develop the recycling which the stage collects to achieve the report to produce 3 Rreport, and male various in company website, may supply the recycling system entrepreneur, the subsidiary company or the business agent obtains the product in the website to open the illustration Ming edition and the product ingredient explained, for opens the solution recycling product the actual work reference.

$\mathrm{RD}$ collect the product recycling opinion according to the subsidiary company and the business agent which the entire related recycling system entrepreneur provides, as well as the product guest sue (damage) and the product improvement opinion, the penetration examination conference appraised the product conforms to the $3 \mathrm{R}$ requirement, the recycling cost estimates as well as proposed the product green ecology design improvement plan, the process design change and the project change flow, will improve the procedure will integrate to the system controls the tube the green design standard database as future new product $\mathrm{C} 0$ to the $\mathrm{C} 2$ product design inspection stage improvement criterion, will be closed loop cycle.

\section{Green Information System}

\subsection{System Architecture}

We design an information system for green product in this research. The system is a platform for supplier and recycles management and it is an application for green design. The integration between the green software system and back-end system is necessary. For example, the internal system about PLM, ERP, VQA, Supplier portal, Customer portal and the external system about TEEMA, public certificate database are connected and they

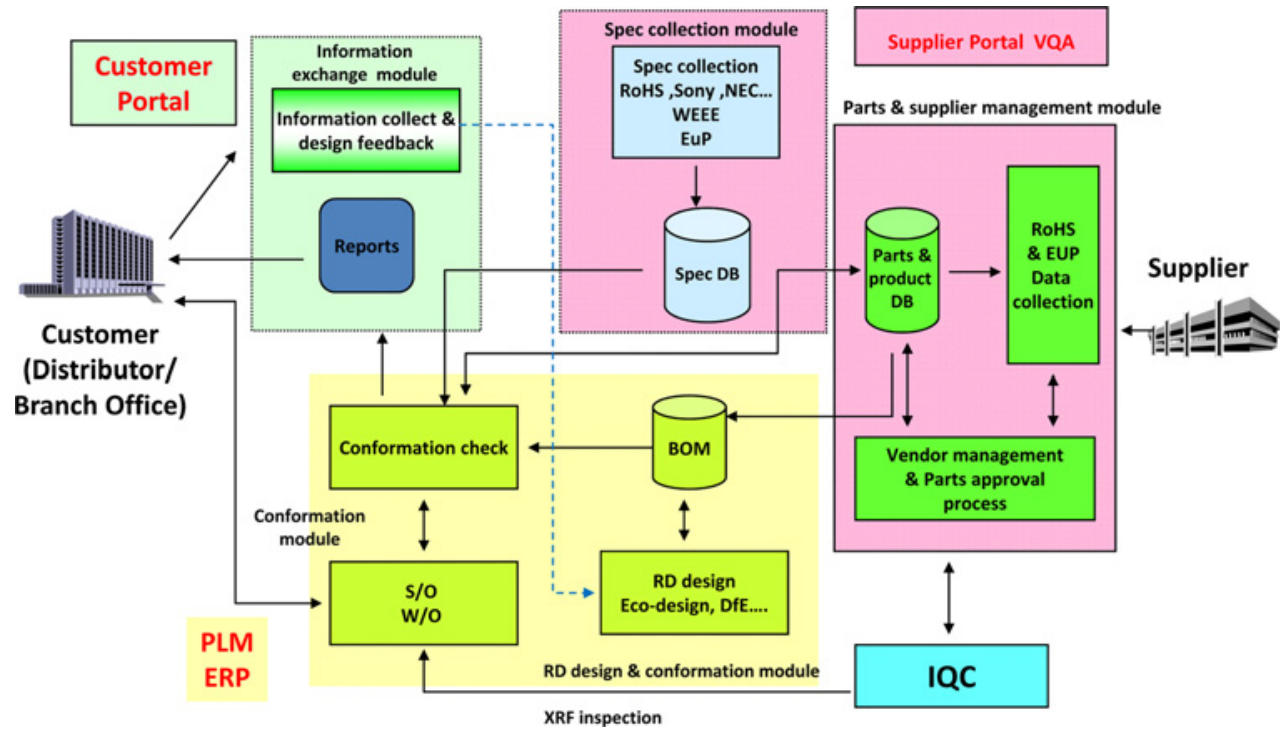

Fig. 8 The architecture of green information system

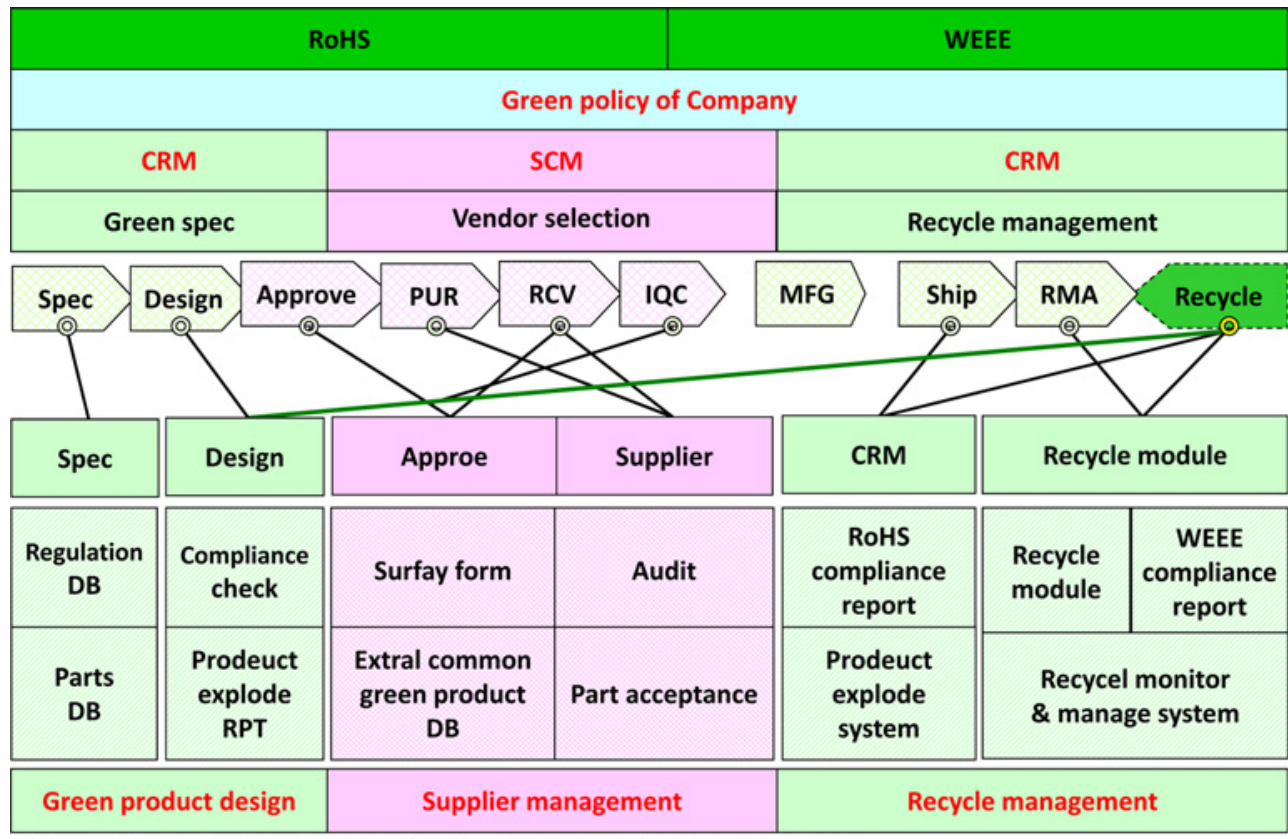

PUR: purchase, RCV: receive, IQC: checklist, MFG: manufacture, RMA: repair

Fig. 9 The function modules of green software system 
can communicate by the green software in a common information standard. The purpose of the information system is to enhance the work and decision efficiency. The Architecture is showed in Fig. 8.

\subsection{System Functions}

Following the operation flow to design the green information system, the function framework is showed in Fig. 9. The green information system consists of 4 function modules: green product design, supplier management, green produce and product recycle.

CRM: Custom Relation Management

SCM: Supply Chain Management

WEEE: Waste Electrical and Electronic Equipment

ICER: Industry Council for electronic Equipment Recycling

EuP: Energy Using Product

RoHS: Restriction of the Use of Certain Hazardous Substances in Electrical and Electronic Equipment

The module of green product design:

(1) To build up the customer green specification database for product design.

(2) To build up the green parts database for product research and design (RoHS is included).

(3) To verify the BOM for hazardous substance on materials and finished goods.

(4) To verify the recycle for hazardous substance on materials and finished goods.

(5) To produce the disassembly statements as a demo.

(6) To integrate PLM system

The module of supplier management:

(1) To build up materials QA system for poison analysis and recyclable assessment.

(2) To verify the green materials with the parts approval process.

(3) To connect external information platform for work efficiency of parts verification.

(4) To inform supplier green parts specification in real time.

(5) To integrate the Procurement system.

The module of green produce:

(1) To divide green and non-green product.

(2) To modify MRP system for old materials in high priority to avoid high inventory storage.

(3) To integrate ERP and Planning system.

The module of product recycle:

(1) To build up the recycle monitor mechanism for product improvement.

(2) To build up recycle prototype for rapid duplicate to another country.

(3) To publish the green performance on internal website.

(4) To integrate Customer portal system.

\subsection{System Implement}

Project manager or R\&D staffs can access the information system to verify the product specification from customers and to query the safe criteria of hazardous substance for judging the quality of each material. If the material fits the criteria, the system will present green mark or the system will show red mark to warm. If the criteria don't be finding, the system will present yellow mark. The system will display the wrong materials and suppliers if the product does not fit the specification. Between the research stage $\mathrm{C} 2$ and $\mathrm{C} 3$, project managers will trace and look up the wrong materials.

\section{Benefits Analysis}

The topic of green is a current trend. Enterprises have to prove the products are produced by them are under green specification. In this chapter, we analysis two green business models, one is with information system and another is no information supporting, it is just with manual work.

\subsection{Cost Analysis}

(1) Hazardous substance list

A. Suppose a product consists of 150 materials. Making a list from one supplier for each material. The common materials are $50 \%$ of total 500 products. On average, it is taking 10 minutes to make one material list. Totally it will spend about 780 days $(150 * 500 * 0.5 * 10 / 60 / 8)$ to make hazardous substance material lists for whole 500 products. It is impossible to market on time.

B. The information system will alarm by e-mail if exceptions are happened on suppliers. With information system, we just focus on exception management. The report said that $65 \%$ of enterprises in Taiwan have joined green business and $90 \%$ of them implement eprocurement information system on web. It only takes 3 minutes for one material list to print out. It will spend about 80 days $(500 * 150 * 0.5 * .35 * 3 / 60 / 8)$ to make hazardous substance material lists.

(2) Audit and tracing

A. It takes 30 minutes to audit one product. For 500 products, it will take 30 days $(500 * 30 / 60 / 8)$ for auditing. If the data from auditing is partial, it can't sure if the product fit the green specification.

B. It only takes 3 minutes to query or print audit report for one product. For 500 products, it will take 3 days to audit them.

(3) Exploded view of the product

A. It spends 10 thousand NT dollars on exploded view chart with outsourcing. For 500 products, it will spend 5 million NT dollars on the chart.

Table 1 The benefits analysis for green information system

\begin{tabular}{|c|c|c|c|c|}
\hline & Item & Manually & Info. System & Benefit \\
\hline \multirow{3}{*}{$\begin{array}{c}\text { Indexes } \\
\text { by } \\
\text { numeric } \\
\text { data }\end{array}$} & $\begin{array}{c}\text { Hazardous } \\
\text { substance data } \\
\text { collection }\end{array}$ & 780 Days & 80 Days & $\begin{array}{l}90 \% \text { costs } \\
\text { saving }\end{array}$ \\
\hline & $\begin{array}{l}\text { Audit and } \\
\text { tracing }\end{array}$ & 30 Days & 3 Days & $\begin{array}{c}90 \% \text { costs } \\
\text { saving }\end{array}$ \\
\hline & $\begin{array}{l}\text { Exploded view } \\
\text { products }\end{array}$ & 5 Million & 2.5 Million & $\begin{array}{c}95 \% \text { costs } \\
\text { saving }\end{array}$ \\
\hline \multirow{2}{*}{$\begin{array}{l}\text { Indexes } \\
\text { non- } \\
\text { numeric } \\
\text { data }\end{array}$} & Reliability & Lower & $\begin{array}{c}\text { Higher for } \\
\text { customers ISO }\end{array}$ & \\
\hline & Advances & Lower & $\begin{array}{l}\text { Higher for new } \\
\text { green condition }\end{array}$ & \\
\hline
\end{tabular}


B. With information system, we have to delivery 10 product samples for verification. Each product sample is 20 thousand NT dollars and 10 product samples are 200 thousand NT dollars. Then it will take 30 minutes on product design for each one. For 500 products, totally it will spend 2.5 million NT dollars on the chart.

\subsection{Quality Analysis}

The risk is happened on manual operations. It should enhance the reliability with information system to support operations whatever customers. On the other hand, suppliers prepare the data and information that are logs for tracing and taking responsibility when the exceptions are happened. Besides European Union, other country will legislate for green clauses. To build up information system to support green operation is necessary because of the efficiency. We sum up some indexes to compare in Table 1.

There are some drawbacks and benefits of those solutions as follows:

(1) UK: Although the British existing recycling system is not perfect, but the British government in the relevant legislation as well as system-driven situation, more positive. The device will have a major local link system to join operations. Retailers recycling of waste electrical and electronic products one by one free assistance; during recycling to pay for these positions, the producer has the responsibility to collect waste electrical and electronic products from these points. The current recovery in the UK Department of larger institutions, after coming through the British territory of WEEE Implementation Act, may be recovered by the organization responsible for operations within the territory of WEEE.

(2) Germany: In the past ten years, Germany have relatively complete operating system, so during the course of recovery and legislation related to the system, the more actively in a mature stage; while Germany also already market saturated in a Waste Electrical and Electronic recycle industry.

(3) France: France and Germany are very similar; but French regulations for imported products provide relevant management has always been stricter than other countries. At present, the department of recycled French system made from recycled tissue SCRELEC responsible recycling of waste batteries, after the French announcement is expected in the relevant laws, SCRELEC will begin to undertake the WEEE recycling business. According to UNEP, 2002 SCRELEC with France (ADEME) in some areas of the pilot project indicated, WEEE recovery were roughly 2.6 kilograms per person per year.

(4) Spain: the central government is currently no special action, and its local government system in recovery operations.

(5) Denmark: has been through the implementation of relevant laws WEEE Directive. System-based recovery led by local governments in Denmark, there are about more than 30 small and medium qualified treatment plant, as the proper handling of WEEE.

\section{Conclusions}

To build up and implement an information system on web with logistic to support green operation is feasible. The information system is proved to be correct under the European Union condition for green in network industry and it will help to enhance the working efficiency. It will save $90 \%$ of costs comparing with manual work.

- For green materials or parts: saving $90 \%$ of costs for operation.

- For product: saving $90 \%$ costs for green verification.

- For exploded report: saving $95 \%$ costs for making a list.

A transferring on business from OEM to own brand is a trend in Taiwan. This paper is for network industry only. And it is a reference for business they are willing to own a brand.

\section{ACKNOWLEDGEMENT}

We thank the National Science Council for funding this research (NSC 102-2221-E-163-003).

\section{REFERENCES}

1. European Commission, "Directive of the European Parliament and of the Council on Waste Electrical and Electronic Equipment (WEEE)," Official Journal of the European Union, 2003.

2. European Commission, "Directive of the European Parliament and of the Council on the Restriction of the Use of Certain Hazardous Substances in Electrical and Electronic Equipment (RoHS)," Official Journal of the European Union, 2003.

3. European Commission, "Proposal for a Directive of the European Parliament and of the Council on Establishing a Framework for the Setting of Eco-Design Requirements for Energy Using Products," Official Journal of the European Union, 2003.

4. Anderson, S., Boike, R., Claussen, J., DelGeorge, L., Eagleson, D., et al., "The Lean and Green Supply Chain: A Practical Guide for Materials Managers and Supply Chain Managers to Reduce Costs and Improve Environmental Performance," Environmental Accounting Projec., 2000.

5. Hammoudeh, M. A., Mancilla-David, F., Selman, J. D., and PapantoniKazakos, P., "Communication Architectures for Distribution Networks within the Smart Grid Initiative," Proc. of the IEEE on Green Technologies Conference, pp. 65-70, 2013.

6. Der Grüne Punkt, "The Letters of the Law," http://www.gruenerpunkt.de/Legal_foundations (Accessed 22 December 2014)

7. EMAS "EMAS Statistics Evolution of Organisations and Sites," $\mathrm{http} / / /$ ec.europa.eu/environment/emas/pdf/5_5articles_en.pdf (Accessed 22 December 2014)

8. European Union Committee, "Advancing Better Regulation in Europe: A Joint UK, Austrian, Finnish Presidency Discussion Paper," in: Ensuring Effective Rgulation in the EU: Follow-Up Report, Britain, G., (Ed.,) pp. 21-22, 2005.

9. Sinn, H.-W., "Public Policies Against Global Warming: A Supply Side Approach," International Tax and Public Finance, Vol. 15, No. 4, pp. 360-394, 2008. 
10. Schoots, K., Kramer, G., and Van Der Zwaan, B., “Technology Learning for Fuel Cells: An Assessment of Past and Potential Cost Reductions,” Energy Policy, Vol. 38, No. 6, pp. 2887-2897, 2010.

11. Shellenberger, M. and Nordhaus, T., "The Creative Destruction of Climate Economics," Breakthrough Journal, 2012.

12. Lomborg, B., "Global Warming Needs a More Innovative Solution," The Financial Times, 2011.

13. Maugeri, L., "Oil: The Next Revolution, the Unprecedented Upsurge of Oil Production Capacity and What It Means for the World," Belfer Center for Science and International Affairs, 2012.

14. Michielsen, T. O., "Strategic Resource Extraction and Substitute Development," Resource and Energy Economics, Vol. 36, No. 2, pp. 455-468, 2014.

15. Mosiño, A., "Using Chebyshev Polynomials to Approximate Partial Differential Equations: A Reply," Computational Economics, Vol. 39, No. 1, pp. 13-27, 2012.

16. Ko, M., Park, S. C., and Chang, M., "Control Level Simulation of an Automatic Storage and Retrieval System in the Automotive Industry," Concurrent Engineering, Vol. 21, No. 1, pp. 13-25, 2013.

17. Lee, G. and Badrul, O., "Optimization for Sustainable Manufacturing based on Axiomatic Design Principles: A Case Study of Machining Processes," Advances in Production Engineering \& Management, Vol. 9, No. 1, pp. 31-43, 2014.

18. Bureau of Economic Analysis, “Annual Industry Accounts," http:// www.bea.gov/about/pdf/ied_annual.pdf (Accessed September 10 2010)

19. Ahn, S.-H., "An Evaluation of Green Manufacturing Technologies based on Research Databases," Int. J. Precis. Eng. Manuf.-Green Tech., Vol. 1, No. 1, pp. 5-9, 2014.

20. Lee, C., Park, J., Kinoshita, M., and Jeong, H., "Development of Intelligent Pad Monitoring System and Application to Analysis of Pressure Distribution in Chemical Mechanical Polishing Process," Int. J. Precis. Eng. Manuf., Vol. 15, No. 9, pp. 2005-2009, 2014.

21. Ahn, S.-H., Chun, D.-M., and Chu, W.-S., "Perspective to Green Manufacturing and Applications," Int. J. Precis. Eng. Manuf., Vol. 14, No. 6, pp. 873-874, 2013.

22. Jeong, M.-S., Lee, S.-K., Yun, J.-H., Sung, J. H., Kim, D. H., et al., "Green Manufacturing Process for Helical Pinion Gear using Cold Extrusion Process,” Int. J. Precis. Eng. Manuf., Vol. 14, No. 6, pp. 1007-1011, 2013.

23. Linke, B., Huang, Y.-C., and Dornfeld, D., "Establishing Greener Products and Manufacturing Processes," Int. J. Precis. Eng. Manuf, Vol. 13, No. 7, pp. 1029-1036, 2012.

24. Lee, Y.-L., Jeong, S.-T., and Park, S.-J., "Study on Manufacturing of Recycled SiC Powder from Solar Wafering Sludge and Its Application,” Int. J. Precis. Eng. Manuf.-Green Tech., Vol. 1, No. 4, pp. 299-304, 2014.
25. Chu, W.-S., Kim, C.-S., Lee, H.-T., Choi, J.-O., Park, J.-I., et al., "Hybrid Manufacturing in Micro/Nano Scale: A Review," Int. J. Precis. Eng. Manuf.-Green Tech., Vol. 1, No. 1, pp. 75-92, 2014.

26. Jo, H., Noh, S. D., and Cho, Y., "An Agile Operations Management System for Green Factory,” Int. J. Precis. Eng. Manuf.-Green Tech., Vol. 1, No. 2, pp. 131-143, 2014.

27. Lee, D. K., Jeong, Y.-K., Shin, J. G., and Oh, D.-K., "Optimized Design of Electric Propulsion System for Small Crafts using the Differential Evolution Algorithm," Int. J. Precis. Eng. Manuf.-Green Tech., Vol. 1, No. 3, pp. 229-240, 2014. 